\title{
WAYFINDING NO CONTEXTO DA ENCONTRABILIDADE DA INFORMAÇÃO: AVALIAÇÃO DOS AMBIENTES INFORMACIONAIS DO DEPARTAMENTO ESTADUAL DE IMPRENSA DO RIO GRANDE DO NORTE
}

\author{
Arthur Ferreira Campos \\ arthurfcampos@hotmail.com \\ Fernando Luiz Vechiato \\ Doutor em Ciência da Informação \\ Professor da UFRN \\ vechiato2008@gmail.com
}

\section{Resumo}

\begin{abstract}
Este artigo fundamenta-se na Encontrabilidade (findability) da Informação, explorando seu atributo wayfinding (orientação espacial) no âmbito da Ciência da Informação. O objetivo geral se reflete em analisar os ambientes informacionais do Departamento Estadual de Imprensa do Estado do Rio Grande do Norte, órgão público que editora o Diário Oficial do $\mathrm{RN}$, na perspectiva da encontrabilidade da informação com base nas recomendações de wayfinding. Para tanto, em um primeiro momento, foi realizada pesquisa bibliográfica para a compreensão dos aspectos teóricos e práticos de wayfinding que auxiliam na encontrabilidade da informação em ambientes informacionais analógicos e digitais. Posteriormente, foi utilizada a técnica de observação para a avaliação do ambiente analógico do referido Departamento (ênfase no arquivo) e seu ambiente digital (web site), com base em recomendações de wayfinding específicas para ambientes informacionais analógicos e digitais, respectivamente. Os resultados revelam que o Arquivo é carente em mecanismos de wayfinding, porque não é disponibilizado um mapa estruturado do ambiente visando facilitar a localização espacial no prédio e, consequentemente, da informação disponível, além de os setores serem semelhantes, não possuindo uma identidade visual própria. $\mathrm{O}$ web site, por sua vez, contempla elementos que favorecem a encontrabilidade da informação, pois sua interface é simples e possui indicadores de rotas percorridas, possibilidades de se fazer o download dos documentos buscados em HTML ou em PDF e indicativos de que a busca foi realizada com êxito.
\end{abstract}

Palavras-chave: Wayfinding. Encontrabilidade da Informação. Ciência da Informação. Ambientes Informacionais. Departamento Estadual de Imprensa do Rio Grande do Norte.

\section{INTRODUÇÃO}

Os ambientes informacionais encontramse numa realidade em que os estudos em Encontrabilidade (findability) da Informação se tornam imprescindíveis para o sucesso no processo de busca informacional. Um ambiente informacional cuja encontrabilidade é carente possui, consequentemente, seu fluxo informacional enfraquecido.

Vechiato e Vidotti (2014) propõem atributos e recomendações para a Encontrabilidade da Informação (EI) em Ambientes Informacionais, quais sejam: taxonomias navegacionais; instrumentos de controle terminológico; folksonomias; metadados; mediação dos informáticos, dos profissionais da informação e dos sujeitos informacionais; affordances; wayfinding; descoberta (acidental) de informações; acessibilidade e usabilidade; intencionalidade; e mobilidade, convergência e ubiquidade.

Neste artigo, tem-se o foco no wayfinding (orientação espacial, traduzido para $\mathrm{o}$ português), que não é um termo nascido na Ciência da Informação, porém suas relações com a EI são perceptíveis para o projeto e para a avaliação de ambientes informacionais. Com isso, wayfinding é um atributo importante para 
localização, locomoção, tomada de decisões e criação de mapas mentais.

O objetivo geral deste artigo é analisar os ambientes informacionais do Departamento Estadual de Imprensa do Estado do Rio Grande do Norte, órgão público que editora o Diário Oficial do RN, na perspectiva da encontrabilidade da informação com ênfase no wayfinding.

A necessidade de incorporar elementos de orientação espacial em ambientes informacionais analógicos e digitais justifica a relevância desta pesquisa, tendo em vista a observação de que muitos ambientes não são projetados considerando esses aspectos, o que dificulta ou inviabiliza a encontrabilidade da informação disponível pelos seus usuários.

\section{WAYFINDING NO CONTEXTO DA ENCONTRABILIDADE DA INFORMAÇÃO}

O termo wayfinding (orientação espacial traduzido) foi utilizado primeiramente na área da Arquitetura e Urbanismo por Kevin Lynch nos anos 1960 compondo o conteúdo de seu livro "The image of city". Nessa perspectiva, o wayfinding está ligado a localização, orientação e sinalização (RIBEIRO, 2009, p. 28).

A abordagem de Lynch refere-se aos elementos de orientação espacial urbanos; ele descreve as seções de legibilidade ambiental (mapas, sinais e qualquer elemento que permita a navegação) como mecanismo comum de todo ser humano. Entretanto, a interdisciplinaridade do wayfinding pode ser notada em trechos contidos em seu livro "The image of city":

Estruturar e identificar o meio ambiente é uma actividade vital de todo o animal móvel. São muitas as espécies de orientações usadas: a sensação visual da cor, da forma, do movimento ou polaridade da luz, assim como outros sentidos, tais como o cheiro, o ouvido, o tacto, a cinestesia, a noção da gravidade, e talvez as de campos magnéticos ou elétricos. (LYNCH, 1960, p. 13).

Consoante a abordagem de Lynch, entende-se que a essência do wayfinding é a estruturação e a identificação, com a finalidade de uma posterior orientação perante o ambiente estudado. $\mathrm{O}$ indivíduo por si só cria mentalmente um mapa para se locomover e se localizar num determinado espaço e, com isso, a abordagem do wayfinding num ambiente informacional não é diferente.

Ribeiro (2009, p. 28) defende que o "wayfinding reflete uma nova abordagem para estudar a movimentação das pessoas e sua relação com o espaço". Nessa proporção, a nova abordagem explicitada contextualiza o ambiente com a locomoção dos sujeitos. Para isso, ela destaca que:

O deslocamento espacial dos indivíduos é visto como um processo onde participam de forma interativa o ser humano, o que implica suas habilidades e aptidões, e o ambiente, suas características. Assim, wayfinding significa o comportamento humano em saber onde está, para onde ir, escolher a melhor rota para o seu destino, reconhecer o local de destino assim que chega nele e ser capaz de inverter o processo e encontrar o caminho de volta (RIBEIRO, 2009, p. 28).

A autora baseia-se na perspectiva que o ser humano precisa interagir mutuamente com o ambiente em que ele está inserido, na medida que ele se encontre e não se perca numa busca casual. O processo descrito por ela é defendido por rotas, sinalizações e mapas indicados por elementos de destaque de trânsito no ambiente.

Partindo desse pressuposto, Costa (2014, p. 12) diz que:

[...] são critérios para a recepção da informação: legibilidade, visibilidade e compreensão visual (sua estética, cor e forma). A recepção dessas informações, para as quais a identificação visual é essencial, pode levar os visitantes a tomar decisões em três níveis: definição de caminhos, direção de caminhos e identificação do destino. O wayfinding sofre influências de diversas variáveis, depende da relação do público/visitante e seu contexto, se está em uma viagem de turismo ou de férias, a trabalho ou em momentos de lazer, em contextos comerciais (shoppings, lojas e etc). Nesses contextos podem ser avaliados como variáveis o tipo de planta, os fluxos, a circulação e as características arquitetônicas, levando em conta, também, a acessibilidade.

Wayfinding é reconhecido por Satalich (1995) em quatro elementos cíclicos, os quais são denominados: Orientação, Decisões de 
rota, Mapeamento mental e Encerramento

(Figura 1).

Figura 1 - Ciclo de wayfinding

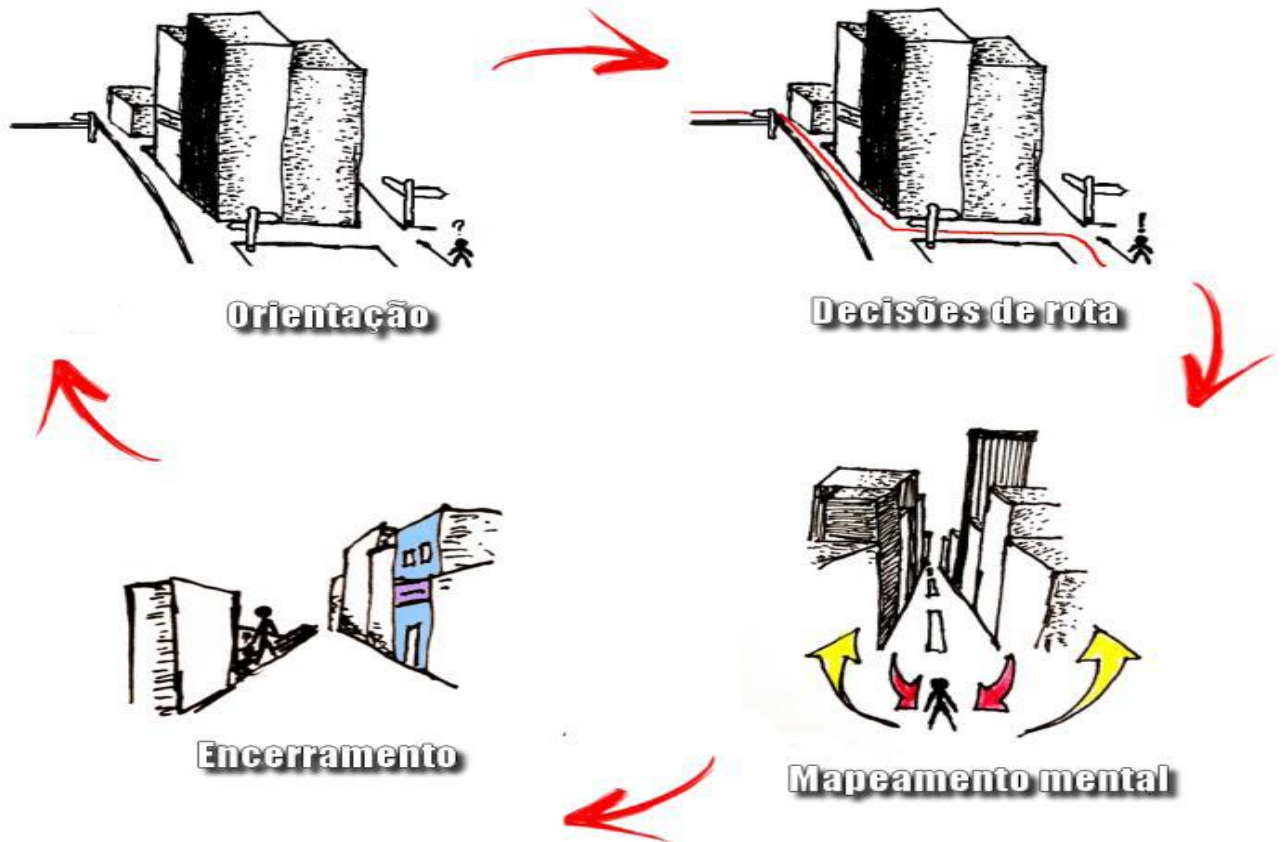

Fonte: Miranda (2015, p. 20), baseado em Satalich (1995).

Nota-se que a orientação mental no ambiente motiva uma determinada decisão de rota que, posteriormente, visa a criação de um mapa mental cuja função é guiar os caminhos no espaço e, por fim, encerra ou recomeça a atividade cíclica.

Considerando que a Ciência da Informação (CI) atualmente está inserida na perspectiva paradigmática pós-custodial (SILVA; RIBEIRO, 2002), objetivando o acesso à informação, e que os estudos teóricos e práticos da CI visam a busca e à recuperação da informação, o wayfinding relaciona-se com o referido campo científico na preocupação com os caminhos que são seguidos para se orientar, com vistas à encontrabilidade da informação desejada.

Miranda (2015, p. 25) diz que:

No processo de busca, o usuário pode se deparar com inúmeras barreiras e desiste do que estava à procura, ou muitas vezes acabar perdido, com um sentimento angustiante e se perguntando "onde estou?", "para onde vou?" e "como retornar para onde estava?". Poucos são os que se aventuram por espaços que não conhecem. Isto ocorre tendo em vista que a maioria das pessoas acredita que irá se perder devido à ausência de elementos que supram a sua necessidade de se orientar no espaço.

Conforme esse pensamento, pode-se inferir que o processo de busca informacional é complexo e se alia às percepções e aos sentimentos do usuário juntamente com variadas barreiras que podem causar a desistência no processo de busca da informação.

Para que a busca de informação num ambiente informacional seja favorável, o wayfinding precisa auxiliar a orientação de como se chega no local, onde se está e saber o caminho inicial visando o retorno (RIBEIRO, 2009). Face a isso, otimizar e acelerar o processo de busca são atividades base do wayfinding, com vistas a favorecer a encontrabilidade da informação disponível.

\section{PROCEDIMENTOS METODOLÓGICOS}


Este estudo se caracteriza preliminarmente como pesquisa bibliográfica, em que se buscou conhecer e correlacionar os conceitos de wayfinding e encontrabilidade da informação no contexto da Ciência da Informação.

Para o cumprimento do objetivo da pesquisa, foi realizada pesquisa exploratória que teve como base a técnica de observação para a análise dos ambientes informacionais do
Departamento Estadual de Imprensa (DEI) do Rio Grande do Norte tendo como ponto de partida as diretrizes de wayfinding propostas por Miranda (2015).

Miranda (2015) propôs diretrizes específicas de wayfinding para ambientes informacionais analógicos e digitais conforme os Quadros 1 e 2:

Quadro 1 - Diretrizes de Wayfinding para ambientes analógicos

\section{Diretrizes}

1. Disponibilizar um mapa bem estruturado do local;

2. Estruturar as rotas de forma que auxiliem a navegação e busca;

3. Oferecer sinalizações ou pistas (affordances) para auxiliar na tomada de decisão;

4. Criar uma identidade para cada espaço, diferenciando-o dos outros;

5. Fornecer características visuais distintas para cada região;

6. Fazer uso de um marco ou ponto de referência para auxiliar o usuário a situar-se no espaço.

Fonte: Miranda (2015, p. 31).

Quadro 2 - Diretrizes de Wayfinding para ambientes digitais Diretrizes

1. Criar um ambiente que permita a encontrabilidade da informação tanto por meio do mecanismo de busca como pelo sistema de descoberta acidental de informação;

2. Oferecer recursos que permitam que o usuário situe-se no site e sempre saiba onde está exatamente;

3. Apresentar um layout objetivo e que não confunda o usuário;

4. Criar uma identidade para cada ambiente do site;

5. Dispor informações para que o usuário consiga saber que achou o que realmente estava querendo encontrar.

\section{Autores}

Morville (2005);

Lynch e Horton (2009)

Lynch e Horton (2009)

Lynch e Horton (2009)

Lynch e Horton (2009)

Morville (2005);

Lynch e Horton (2009)

Fonte: Miranda (2015, p. 34).

As referidas diretrizes serviram de base, portanto, para a análise dos ambientes informacionais do referido Departamento. Em relação ao ambiente analógico, analisou-se o arquivo do jornal Diário Oficial do Estado do Rio Grande do Norte responsável por disponibilizar esses jornais para a comunidade e, em relação ao ambiente digital, foi realizada a análise do site do Diário Oficial do $\mathrm{RN}$ (http://www.diariooficial.rn.gov.br/), responsável por prover e divulgar os jornais tanto como assuntos administrativos e internos.

\subsection{DEPARTAMENTO ESTADUAL DE IMPRENSA: HISTÓRIA E MISSÃO ${ }^{1}$}

O DEI é o órgão governamental cuja responsabilidade primordial é editorar o jornal "Diário Oficial" do Rio Grande do Norte, o qual é essencial para consultas referentes a assuntos públicos como: editais de concursos,

\footnotetext{
${ }^{1}$ As informações presentes nesta seção foram baseadas no web site do Departamento Estadual da Imprensa (http://www.dei.rn.gov.br/)
} 
aposentadorias dos servidores, nomeações, exonerações, leis, decretos, portarias, publicações das secretarias do governo do Estado, publicações particulares de empresas públicas e privadas, entre outros.

Também é responsável por outros tipos de publicações de relacionadas ao Estado como livros, folhetos, revistas etc., bem como gerir serviços gráficos integrais (oficiais ou não).

Historicamente, no Rio Grande do Norte, o Diário Oficial surgiu do jornal "A República" que foi criado por Pedro Velho de Albuquerque Maranhão. O jornal, como o nome induz, era partidário e servia para disseminar informações e ideias republicanas no $\mathrm{RN}$, tendo sua primeira edição de circulação em $1^{\circ}$ de julho de 1889 . Devido a vitória e proclamação da República, o jornal "A República" divulgava assuntos oficiais do governo, porém ainda não era um noticiário vinculado ao governo.

O governador Juvenal Lamartine de Faria, na data de 28 de janeiro de 1928, nomeando o jornalista Cristóvão Dantas como primeiro diretor do órgão, fez nascer a "Imprensa Oficial do Rio Grande do Norte" colocando "A República" como corpo oficial do Estado.

Na Era Vargas, especificamente no Estado Novo, o interventor Aldo Fernandes Raposo de Melo, num decreto de 27 de junho de 1941, trocou a denominação "Imprensa Oficial" por "Departamento Estadual de Imprensa e Propaganda (DEIP)" com visão semelhante ao Departamento de Imprensa e Propaganda (DIP) do governo de Getúlio Vargas. Com novo nome e novas atividades, o DEIP teve o jornalista Edílson Cid Varela como primeiro diretor.

Em 13 de dezembro de 1945, o interventor Miguel Seabra Fagundes, nomeou o DEIP como "Departamento Estadual de Informações" tornando o jornalista Aderbal de França como diretor. Posteriormente, em 1948, o órgão veio a se denominar "Departamento Estadual de Imprensa" pela intervenção do governador José Augusto Varela.

A "Companhia Editora do Rio Grande do Norte (CERN)" criada pelo governador Cortez Pereira foi essencial para a história do Departamento Estadual de Imprensa do RN pois, no mandato de José Agripino Maia, segundo o decreto $\mathrm{n}^{\circ}$. 12.085, de 29.03.94, foi publicado e oficializado o 'novo' DEI, apoderando-se do acervo da CERN (que se alocou com o DEI) e incrementado seu material informacional.

Nesses 128 anos, o Departamento Estadual de Imprensa já foi associado ao Gabinete Civil do Estado e em 1996, associou-se a Assessoria de Comunicação Social permanecendo até hoje nessa aliança. Nesses tempos de associações e mudanças, o Diário Oficial já teve sua circulação interrompida, isto é, primeiramente circulava dentro do jornal "A República" a cada cinco dias, tendo sua primeira edição isolada em 20 de novembro de 1932. Nos dias de hoje, o Diário Oficial circula de terça a sábado e o jornal "A República" depois de várias desativações - teve sua última veiculação em 1987.

O Diário Oficial do Estado do RN, em âmbitos tecnológicos, dota de uma das mais recentes 'ilhas gráficas' (maquinário de produção) do Estado e é favorável a constante modernização e adequação às tecnologias editoriais existentes.

Quanto à localização do Departamento Estadual de Imprensa, atualmente, está referida na Avenida Câmara Cascudo, número 355 no bairro histórico e memorial da Ribeira, contudo já teve outros endereços e sedes no decorrer da história.

Hoje sua estrutura organizacional baseiase em quatro cargos de livre nomeação e livre exoneração, sendo: um diretor-geral, um coordenador e dois subcoordenadores. Como missão, compete a "atender, cada vez melhor os seus usuários e clientes, continuando a ser um prestador de serviço ao povo do Rio Grande do Norte" (SITE do DEI, 2017).

\section{ANÁLISE DOS DADOS E DISCUSSÃO DOS RESULTADOS}

A análise presente nesta seção foi realizada com base nas diretrizes de wayfinding propostas por Miranda (2015), apresentadas na seção 3, para avaliar os ambientes informacionais (analógico e digital) do Departamento Estadual de Imprensa do Estado do Rio Grande do Norte. Como já explicitado, o arquivo se caracteriza como um ambiente informacional analógico e o site (http://www.diariooficial.rn.gov.br/) do referido Departamento se caracteriza como um ambiente informacional digital. Ambos os 
ambientes são destinados a consultas relacionadas à assuntos de caráter público.

\subsection{ANÁLISE DO AMBIENTE INFORMACIONAL ANALÓGICO}

Dentro do prédio, estão letras pequenas indicando que ali é o Diário Oficial do RN, órgão do governo estadual. Antes, ali era publicado o jornal "A República”, o qual parou de circular em 1987. A imagem abaixo (Figura 2) indica a sinalização para as letras "A República”.

Figura 2 - Fachada do Departamento Estadual da Imprensa

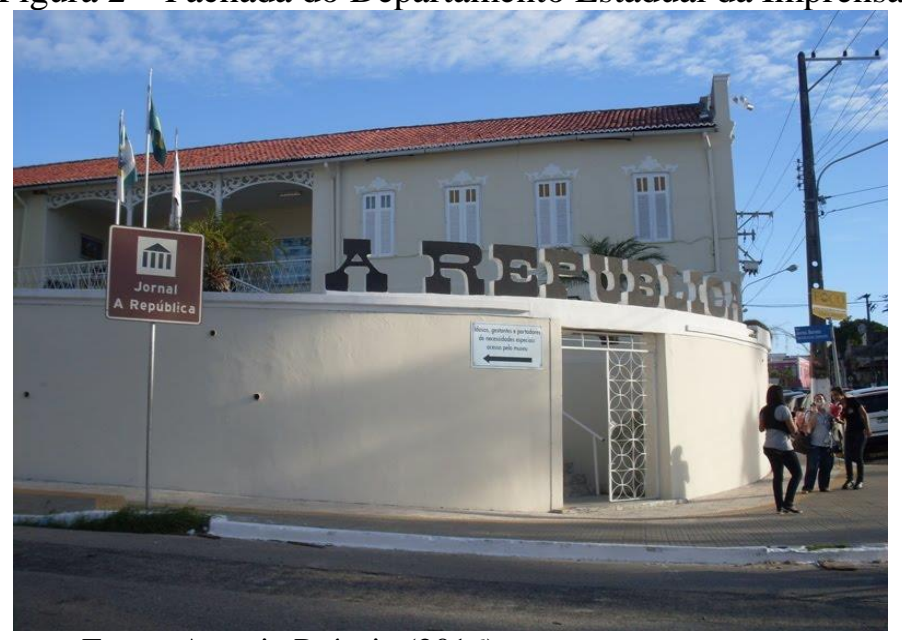

Fonte: Autoria Própria (2016).

Conforme Miranda (2015, p. 31), a primeira diretriz de wayfinding é "Disponibilizar um mapa bem estruturado do local", o que não é visto no Departamento Estadual da Imprensa. Para se localizar espacialmente, a segunda diretriz de Miranda (2015, p.31) diz que o ambiente analógico deve "Estruturar as rotas de forma que auxiliem a navegação e busca". Isso não é visto no DEI já que, ao chegar no prédio, deve-se solicitar informação na recepção. Por motivos particulares, não se pôde fotografar a recepção. Passando desta, há um corredor indicando o arquivo numa placa em amarelo com letras pretas. De acordo com a Figura 3, o corredor é ao lado da recepção.

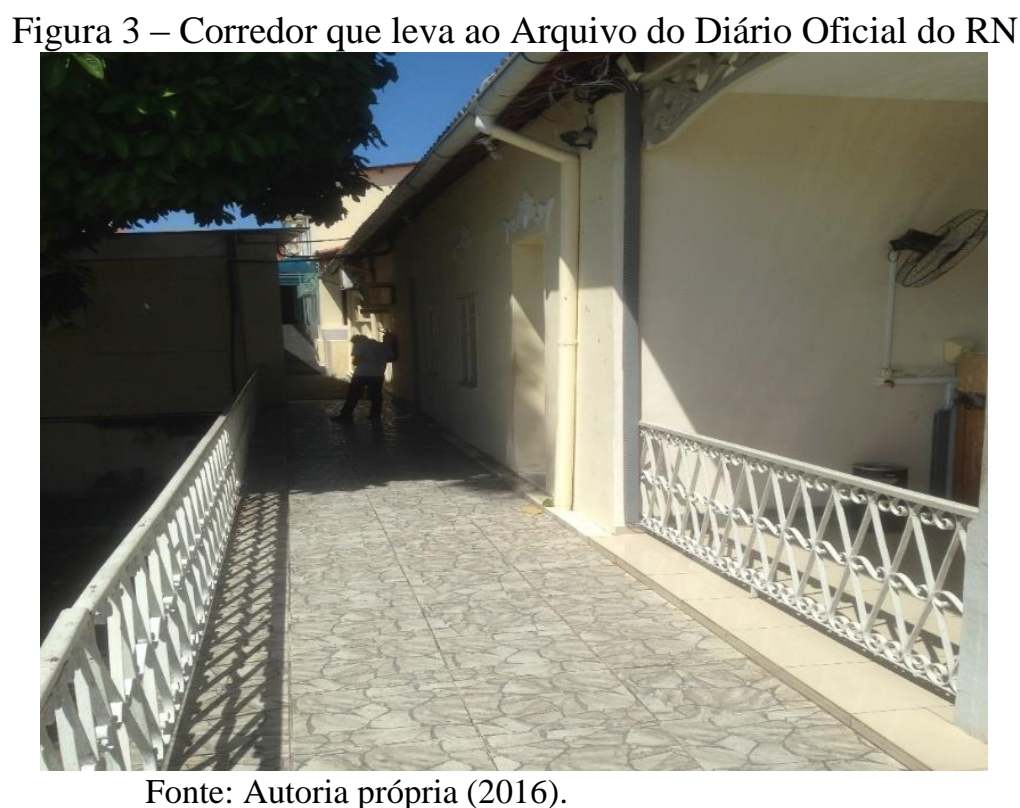


Na Figura 4, percebe-se, logo no caminho deste corredor, a sinalização da porta do setor de Arquivo.

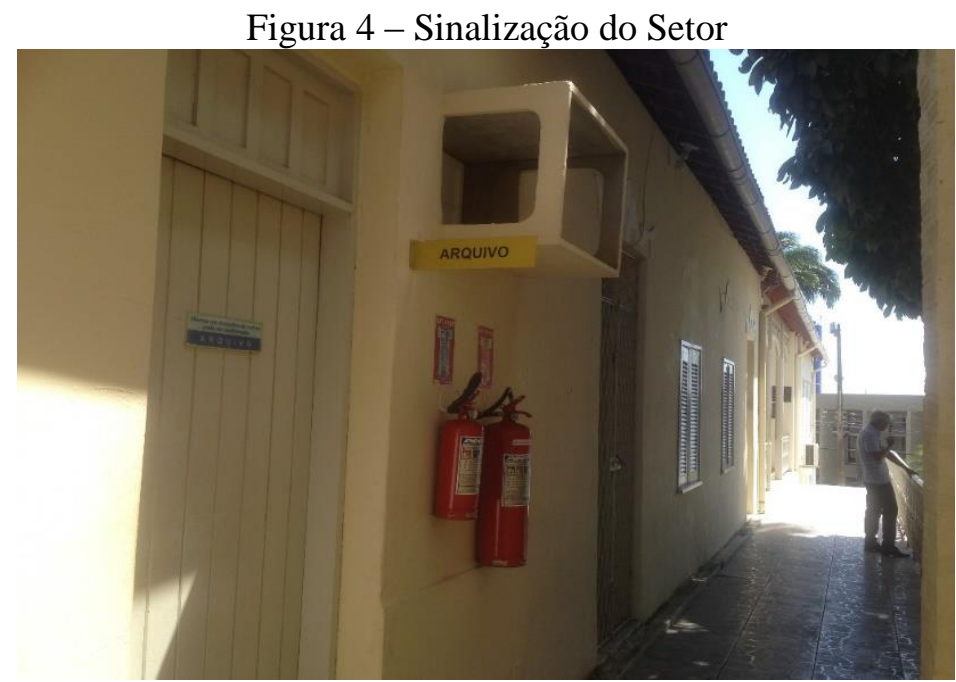

Fonte: Autoria própria (2016).

Sendo assim, a terceira diretriz de Miranda (2015, p.31), à qual diz que o ambiente analógico deve "Oferecer sinalizações ou pistas (affordances) para auxiliar na tomada de decisão", é vista nas plaquinhas de indicação. A plaquinha em dois tons de azul sinaliza novamente que ali funciona $o$ arquivo, mas não indica se é o arquivo do Diário Oficial e, sendo ali uma empresa de editoração, ali poderia ser o arquivo processual ou qualquer outro arquivo. Acima da plaquinha, segue uma frase de efeito em relação ao trabalho realizado ali, como a imagem abaixo indica (Figura 5).

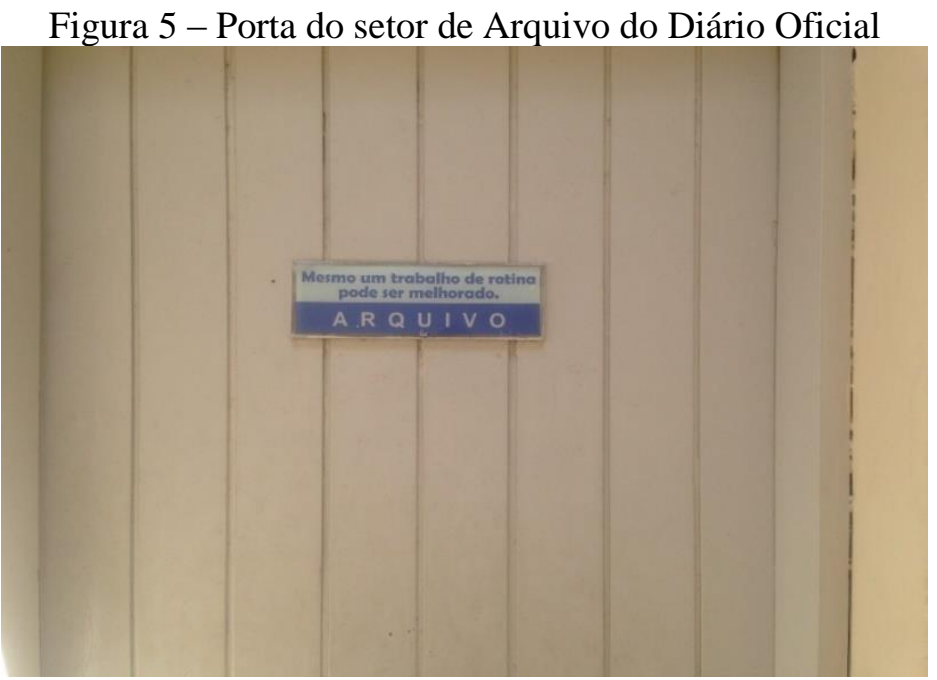

Fonte: Autoria própria (2016).

A quarta diretriz de Miranda (2015, p.31) indica que um ambiente analógico deve "Criar uma identidade para cada espaço, diferenciando-o dos outros" e isso não é visto. Percebe-se na FIGURA 4 que a entrada do outro setor é semelhante a entrada do arquivo, sendo diferenciada pela grade, pois aquela porta está inutilizada.

Na quinta diretriz de Miranda (2015, p.31), que diz que o ambiente analógico deve "Fornecer características visuais distintas para cada região" também não é aplicada ao DEI, justamente pela distinção visual dos setores ser 
uma placa em dois tons de azul. $\mathrm{O}$ arquivo não pôde ser fotografado por dentro.

A sexta diretriz de Miranda (2015, p.31) diz que o ambiente analógico deve "Fazer uso de um marco ou ponto de referência para auxiliar o usuário a situar-se no espaço". A partir disso, considera-se que o processo de busca informacional não é autônomo, necessitando sempre do supervisor para ajudálo a se localizar. O 'marco ou ponto de referência' pode ser aplicado à recepção.

\subsection{ANÁLISE DO AMBIENTE INFORMACIONAL DIGITAL}

O site do Diário Oficial do Estado do RN (http://www.diariooficial.rn.gov.br/) é uma alternativa para suprir barreiras geográficas. Miranda (2015, p.34) diz que a primeira diretriz de wayfinding para um ambiente digital é "Criar um ambiente que permita a encontrabilidade da informação tanto por meio do mecanismo de busca como pelo sistema de descoberta acidental de informação". Com isso, o site é interativo, com facilidade de encontrar um documento tanto pela busca na aba 'EDIÇÃO DO DIA', quanto pelo 'PESQUISA' no meu principal (Figura 6).

Figura 6-Homepage do site

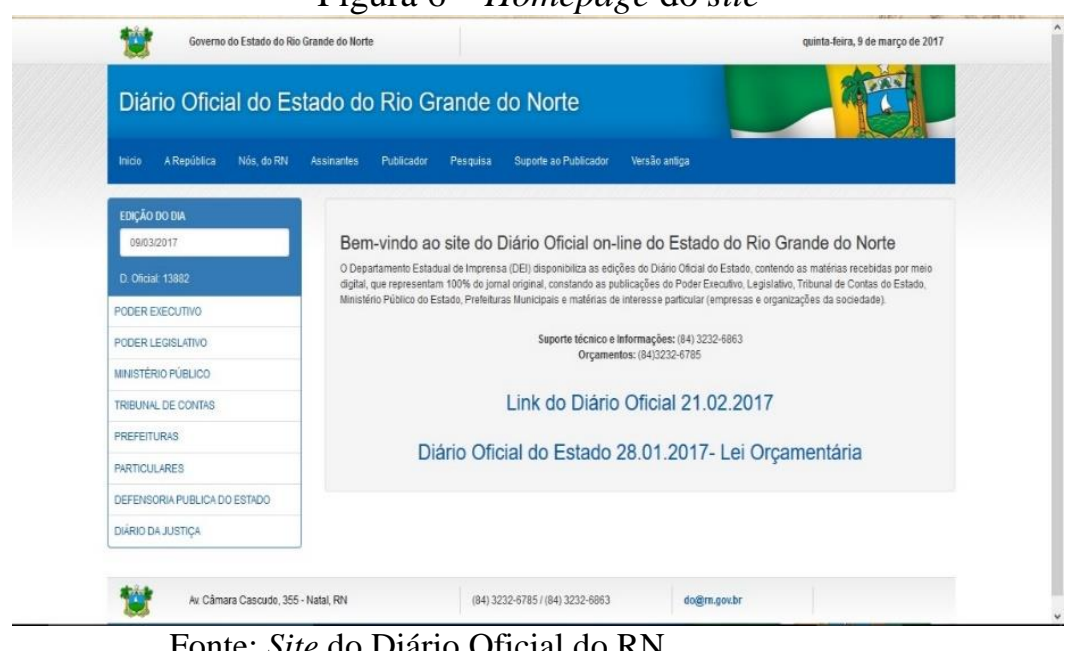

A segunda diretriz de Miranda (2015, p.34) diz que o ambiente digital deve "Oferecer recursos que permitam que o usuário situe-se no site e sempre saiba onde está exatamente".
A partir disso, pressionando a aba 'PODER EXECUTIVO', o site indica a figura seguinte lembrando sua opção de busca (Figura 7).

Figura 7 - Site direcionado

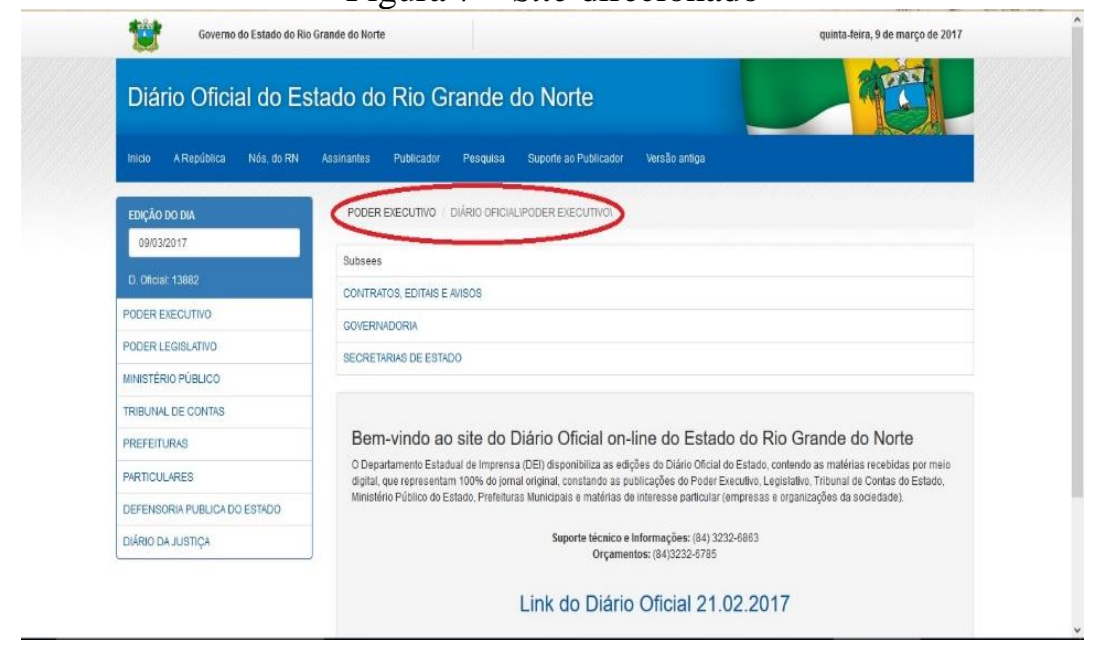

Fonte: Site do Diário Oficial do RN. 
A terceira diretriz de Miranda (2015, p.34) diz que o ambiente digital deve "Apresentar um layout objetivo e que não confunda o usuário"; o site possui layout agradável, porém o excesso de letras maiúsculas dificulta a legibilidade, aludindo que as palavras em letras maiúsculas são mais relevantes do que as com letras minúsculas.
A quarta diretriz de Miranda (2015, p.34) diz que o ambiente digital deve "Criar uma identidade para cada ambiente do site". Isso não é percebido, pois, as páginas do site são parecidas. Como exemplo, as Figuras 8 e 9 mostram uma busca na aba 'PODER LEGISLATIVO' e outra na aba 'MINISTÉRIO PÚBLICO'.

Figura 8 - Busca na aba Poder Legislativo

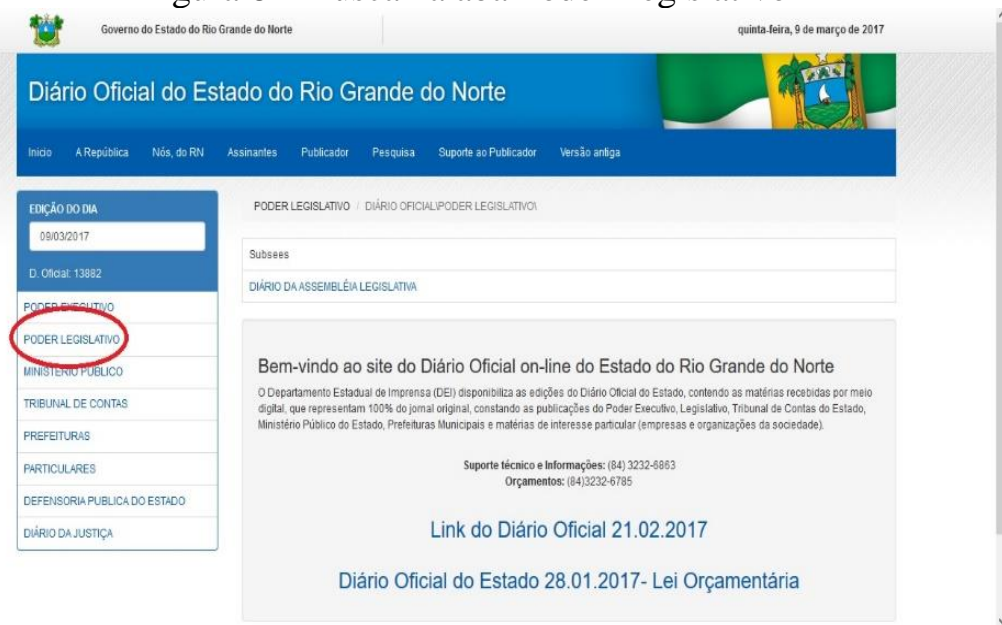

Fonte: Site do Diário Oficial do RN.

Figura 9 - Busca na aba Ministério Público

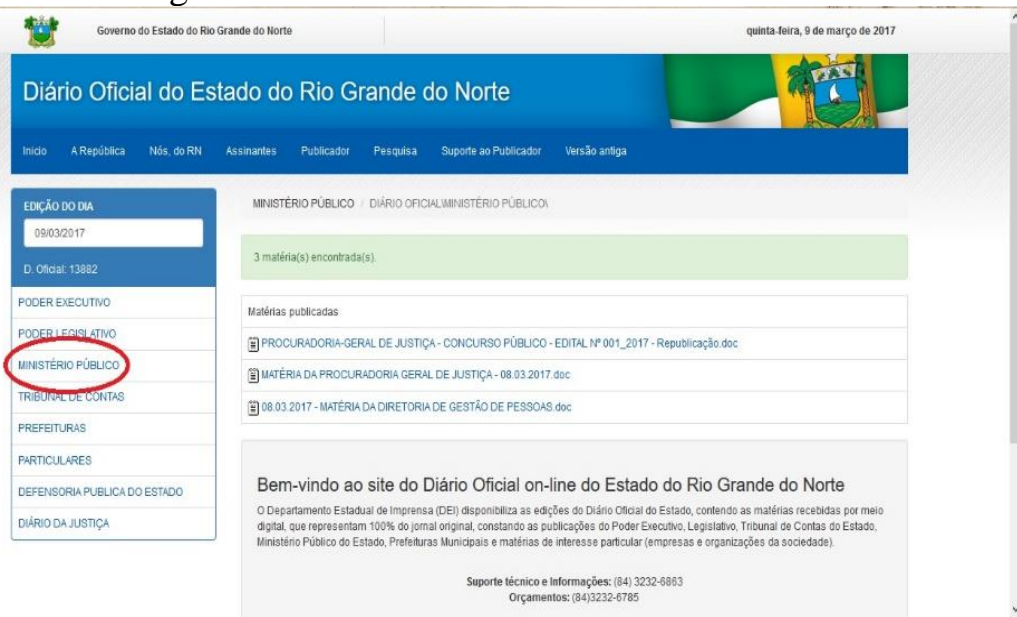

Fonte: Site do Diário Oficial do RN.

A quinta diretriz de Miranda (2015, p. 34) diz que o ambiente digital deve "Dispor informações para que o usuário consiga saber que achou o que realmente estava querendo encontrar". A Figura 10 indica a parte de pesquisa, possibilitando uma busca HTML ou PDF. Optou-se pela busca em PDF do dia 09/03/2017. Nos 'RESULTADOS DA BUSCA', percebe-se os elementos que indicam que o documento. 
Figura 10 - Busca de jornal do site do Diário Oficial

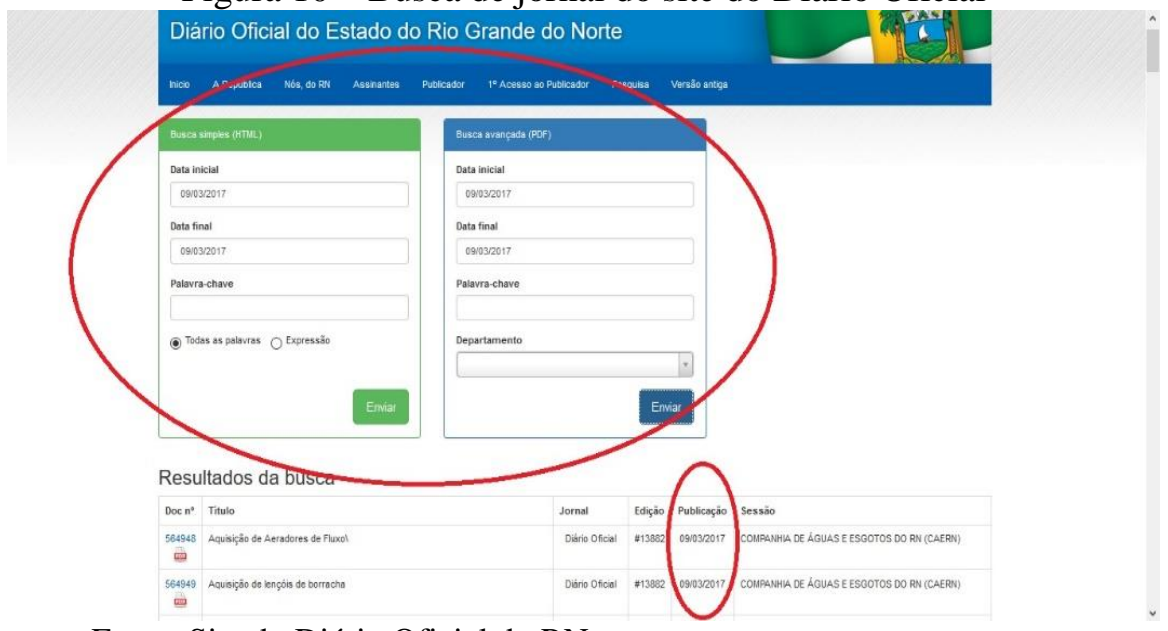

Fonte: Site do Diário Oficial do RN.

\section{CONSIDERAÇÕES FINAIS}

O Wayfinding beneficia o fluxo de informação nos ambientes informacionais; esse termo, criado para designar mapas e rotas geográficas, pode ser incorporado à Ciência da Informação, aprimorando a organização, a estruturação e a apresentação do ambiente informacional, favorecendo a busca informacional e a encontrabilidade da informação.

Conforme a análise dos espaços analógico e digital (arquivo e o site do Diário Oficial), percebe-se que é complicado inferir que o arquivo do Diário Oficial funciona no prédio escrito 'A REPUBLICA' acima de seu portão central.

$\mathrm{O}$ ambiente analógico carece de pontos positivos na localização devido à ausência de autonomia na busca informacional, sendo necessário perguntar na recepção sobre 'onde se está', 'para onde ir' ou 'como chegar'. Não disponibilizar um mapa do local resulta em confusão dentro do prédio porque os setores são semelhantes, ou seja, aproximam-se na identidade.

Diferindo, o ambiente digital (site) apresenta pontos positivos perante as diretrizes propostas por Miranda (2015), apresentando interface simplificada com recursos indicadores de rotas percorridas. Esses são importantes para saber onde o usuário está, como chegou e como voltar. Seu ponto fraco é a falta de identidade aos ambientes internos com páginas parecidas em cor e tamanho de letras podendo resultar em perda do foco da busca.

Em suma, a aplicação do wayfinding relacionado à Ciência da Informação precisa ser utilizada e pesquisada mais frequentemente se referindo a um objeto específico, podendo direcionar a implementação de ambientes informacionais com vistas para a orientação espacial dos usuários, visando melhorias na autonomia do processo de busca.

Recebido em: 13/04/2017

Aceito em definitivo em: 22/05/2017 


\title{
WAYFINDING IN THE CONTEXT OF INFORMATION FINDABILITY: EVALUATION OF INFORMATIONAL ENVIRONMENTS OF THE STATE PRESS DEPARTMENT OF RIO GRANDE DO NORTE
}

Abstract

\begin{abstract}
This article is based on the Information Findability, exploring its wayfinding attribute (spatial orientation) in the scope of Information Science. The general objective is reflected in analyzing the informational environments of the State Department of Press of the State of Rio Grande do Norte, public agency that publishes the Official Gazette of the RN, in the perspective of the information findability based on the recommendations of wayfinding. In order to do so, at first, a bibliographical research was carried out to understand the theoretical and practical aspects of wayfinding that aid in the information findability in analogical and digital information environments. Subsequently, the observation technique was used to evaluate the analog environment of the said Department (emphasis in the archive) and its digital environment (web site), based on recommendations of specific wayfinding for analogical and digital information environments, respectively. The results show that the archive is lacking in wayfinding mechanisms, because a structured map of the environment is not available, in order to facilitate the spatial location in the building and, consequently, the available information, besides the sectors being similar, not having a proper visual identity. The web site, in turn, includes elements that favor information findability, because its interface is simple and has indicators of routes traveled, possibilities to download the documents sought in HTML or PDF and indicative that the search was successfully.
\end{abstract}

Keywords: Wayfinding. Information findability. Information Science. Information Environments. State Department of Press of Rio Grande do Norte.

\section{REFERÊNCIAS}

COSTA, R. X. da. Percepção ambiental em museus paisagens de arte contemporânea: a legibilidade dos museus no Inhotim/Brasil e em Serralves/Portugal avaliada pelo público visitante. 2014. 388 f. Tese (Doutorado em Conforto no Ambiente Construído; Forma Urbana e Habitação) - Universidade Federal do Rio Grande do Norte, Natal, 2014.

Disponível em:

https://repositorio.ufrn.br/jspui/handle/123456 789/12320. Acesso em: 14 mar. 2017.

DIÁRIO OFICIAL DO ESTADO DO RIO GRANDE DO NORTE, S. D. Governo do Estado do Rio Grande do Norte. Disponível em: <http://www.diariooficial.rn.gov.br/>. Acesso em: 09 mar. 2017.

IMPRENSA, D. E. de. Governo do Estado do Rio Grande do Norte. Disponível em: <http://www.dei.rn.gov.br/>. Acesso em: 03 mar. 2017.

LYNCH, K. A imagem da cidade. São Paulo: Massachusetts Institute of Technology and the President and Fellows of Harvard College, 1960.

LYNCH, P. J.; HORTON, S. Web style guide: basic design principles for creating web sites. 3. ed. 2009. Disponível em: < http://webstyleguide.com/wsg3/>. Acesso em: 08 mar. 2017.

MIRANDA, E. B. S. de. Encontrabilidade da Informação em Ambientes Informacionais: identificação de elementos de Wayfinding presentes no acervo da BCZM e no catálogo online do SIGAA. 2015. $49 \mathrm{f}$. Monografia (Bacharelado) - Curso de Graduação em Biblioteconomia. Universidade Federal do Rio Grande do Norte. Natal.

MORVILLE, P. Ambient findability.

Sebastopol: O’Really, 2005.

RIBEIRO, L. G. Onde estou? Para onde vou? Ergonomia do ambiente construído: Wayfinding e Aeroportos. 120 f. 2009. Tese de Doutorado. Dissertação (Doutorado em Design) - Pontifícia Universidade Católica do 
Rio de Janeiro, Rio de Janeiro. Disponível em: <http://www.dbd.puc-

rio.br/pergamum/biblioteca/php/index.php?co dObra $=0 \& \operatorname{codAcervo}=179601 \&$ posicao_atua $\underline{\mathrm{l}=142 \& \text { posicao_maxima }=355 \& \text { tipo }=\mathrm{bd} \& \mathrm{cod}}$ $\mathrm{Bib}=0 \& \operatorname{codMat}=\&$ flag $=\&$ desc $=\&$ titulo $=$ Publi ca\%E7\%F5es\%20On-

Line\&contador $=0 \&$ parcial $=\&$ letra $=0 \&$ lista $=$ E>. Acesso em: 15 mar. 2017.

\section{SATALICH, G.A., Navigation and} Wayfinding in Virtual Reality: Finding Proper Tools and Cues to Enhance Navigation Awareness, Master's Thesis, University of Washington, 1995. Disponível em
$<$ ftp://hitl.washington.edu/pub/publications/sa talich/th-95-4.pdf>. Acesso em: 26 jan. 2017.

SILVA, A. M. da. RIBEIRO, F. Das

<<ciências>> documentais à Ciência da Informação: ensaio epistemológico para um novo modelo curricular. Porto: Ed.

Afrontamento, 2002.

VECHIATO, F. L.; VIDOTTI, S. A. B. G. Encontrabilidade da informação. 1. ed. São Paulo: Cultura Acadêmica, 2014. (Coleção PROPG Digital- UNESP). ISBN 9788579835865. Disponível em: <http://hdl.handle.net/11449/126218>. Acesso em: 15 mar. 2017 